\title{
Effect of a community health worker mHealth monitoring system on uptake of maternal and newborn health services in Rwanda
}

\author{
Celestin Hategeka ${ }^{1,2^{*}}$ (D) Hinda Ruton ${ }^{1,3}$ and Michael R. Law ${ }^{1}$
}

\begin{abstract}
Background: In an effort to improve access to proven maternal and newborn health interventions, Rwanda implemented a mobile phone (mHealth) monitoring system called RapidSMS. RapidSMS was scaled up across Rwanda in 2013. The objective of this study was to evaluate the impact of RapidSMS on the utilization of maternal and newborn health services in Rwanda.

Methods: Using data from the 2014/15 Rwanda demographic and health survey, we identified a cohort of women aged 15-49 years who had a live birth that occurred between 2010 and 2014. Using interrupted time series design, we estimated the impact of RapidSMS on uptake of maternal and newborn health services including antenatal care (ANC), health facility delivery and vaccination coverage.

Results: Overall, the coverage rate at baseline for ANC (at least one visit), health facility delivery and vaccination was very high (> 90\%). The baseline rate was 50.30\% for first ANC visit during the first trimester and $40.57 \%$ for at least four ANC visits. We found no evidence that implementing RapidSMS was associated with an immediate increase in ANC (level change: $-1.00 \%$ (95\% Cl: -2.30 to 0.29 ) for ANC visit at least once, $-1.69 \%$ (95\% Cl: -9.94 to 6.55) for ANC (at least 4 visits), -3. $80 \%$ (95\% Cl: -13.66 to 6.05 ) for first ANC visit during the first trimester), health facility delivery (level change: $-1.79,95 \% \mathrm{Cl}$ : -6.16 to 2.58 ), and vaccination coverage (level change: $0.58 \%$ (95\%Cl: -0.38 to 1.55 ) for BCG, $-0.75 \%$ (95\% Cl: -6.18 to 4.67 ) for polio 0). Moreover, there was no significant trend change across the outcomes studied.

Conclusion: Based on survey data, the implementation of RapidSMS did not appear to increase uptake of the maternal and newborn health services we studied in Rwanda. In most instances, this was because the existing level of the indicators we studied was very high (ceiling effect), leaving little room for potential improvement. RapidSMS may work in contexts where improvement remains to be made, but not for indicators that are already very high. As such, further research is required to understand why RapidSMS had no impact on indicators where there was enough room for improvement.
\end{abstract}

Keywords: Maternal and newborn health, mHealth, RapidSMS, Interrupted time series analysis, Rwanda demographic and health survey

\footnotetext{
*Correspondence: celestin.hategeka@alumni.ubc.ca

'Centre for Health Services and Policy Research, Faculty of Medicine, School

of Population and Public Health, The University of British Columbia, 201-2206 East Mall, Vancouver, BC V6T1Z3, Canada

${ }^{2}$ Collaboration for Outcomes Research and Evaluation, Faculty of

Pharmaceutical Sciences, The University of British Columbia, Vancouver, BC,

Canada

Full list of author information is available at the end of the article
}

(c) The Author(s). 2019 Open Access This article is distributed under the terms of the Creative Commons Attribution 4.0 International License (http://creativecommons.org/licenses/by/4.0/), which permits unrestricted use, distribution, and reproduction in any medium, provided you give appropriate credit to the original author(s) and the source, provide a link to the Creative Commons license, and indicate if changes were made. The Creative Commons Public Domain Dedication waiver (http://creativecommons.org/publicdomain/zero/1.0/) applies to the data made available in this article, unless otherwise stated. 


\section{Introduction}

Improving maternal, newborn and child health outcomes remains one of the most significant challenges for lowand middle- income countries (LMICs) [1, 2]. Reducing under-five child and maternal mortality by two-thirds and three-quarters between 1990 and 2015 were two of the eight United Nations Millennium Development Goals (MDG) [3]. Globally, considerable improvement in maternal, newborn, and child survival has been registered over the MDG era, with the maternal mortality ratio (MMR) reduced by $45 \%$ and under-five mortality reduced by more than half (53\%) by 2015 [4]. Nevertheless, the improvement has not been homogenous across countries and, in fact, only a third of countries (62) achieved the fourth MDG while only nine countries met the fifth MDG by 2015 [1, 2].

Rwanda has made impressive progress with regards to improving maternal and newborn and child survival post-1994 genocide [5-7]. Although Rwanda achieved the maternal and child health-related MDGs, the neonatal mortality rate (MNR) and maternal mortality ratio (MMR) remain high and could be reduced significantly with timely access to quality health services across the continuum of care for mothers and newborns [8]. Rwanda's NMR and MMR are currently estimated at 20 deaths per 1000 live births and 210 deaths per 100,000 live births, respectively [9]. Therefore, efforts are still required for the country to achieve the recently adopted United Nations' Sustainable Development Goals (SDGs) (i.e. SDG targets \# 3.1 and 3.2: reduce maternal mortality to less than 70 per 100,000 live births and neonatal mortality to at least as low as 12 per 1,000 live births by 2030) [10]. Currently, the leading causes of neonatal mortality include birth asphyxia, prematurity, and neonatal infections; while hemorrhage, obstructed labor, sepsis, and hypertensive disorders of pregnancy are the leading causes of maternal deaths in Rwanda [11, 12]. Most of these deaths are preventable with timely access to proven maternal and newborn health interventions $[1,13]$. Unfortunately, while the knowledge of most of the interventions needed to improve maternal and newborn survival has advanced remarkably since the adoption of the MDGs, healthcare systems in many LMICs do not effectively deliver currently recommended life-saving maternal and newborn health interventions including antenatal and post-natal care $[1,13]$.

Evidence suggests that effective coverage of proven health interventions across the continuum of maternal and newborn care could lead to a substantial reduction in maternal and neonatal mortality in LMICs $[8,10]$. Bhutta and colleagues estimated that increasing coverage and quality of preconception, antenatal, intrapartum and postnatal interventions (already proven to be effective) by 2025 could prevent approximately two-thirds of neonatal deaths, one-third of stillbirths, and over half of maternal deaths annually [8]. In an effort to increase uptake of proven maternal and newborn healthcare services and, ultimately, improve maternal and newborn health, Rwanda has been using an SMS based alert system called RapidSMS [14]. RapidSMS is a free and open source platform for mobile alert systems [15]. This mhealth platform was modified for use in Rwanda to facilitate communication between community health workers and the ambulance system, health facilities staff, and the central government.

The use of mhealth interventions has been increasing globally, with approximately $83 \%$ of World Health Organization (WHO) member countries reporting having one mhealth initiative in 2016 [16]. At the same time, however, there is a paucity of evaluations undertaken in these countries to provide evidence on whether these mhealth programs are indeed effective [16]. Therefore, the objective of this study was to evaluate the impact of the RapidSMS program on the utilization of maternal and newborn healthcare services in Rwanda.

\section{Methods}

\section{Study context}

Rwanda is a small, landlocked, and low-income country located in East Africa, with a population of over 11 million [17]. Community health workers (CHWs), who follow up pairs of mother-infant in their villages, were trained and equipped with mobile phones to allow interactive real time two-way communication with the health ambulance system (in case of emergency), health facility staff, district hospital and the central level for action to improve access to antenatal care, postnatal care, health facility delivery, and emergency obstetrical and neonatal care [14]. These CHWs identify pregnant women in their village and make follow-ups across the continuum of care for maternal, newborn and child health to improve utilization of recommended health services [14].

Using mobile phones provided as part of the RapidSMS program, CHWs record new pregnancies (including mother/ infant identification and the first day of the last menstrual period) into the RapidSMS system. They also collect danger signs and symptoms suggestive of potential life-threatening event that warrant urgent attention [14]. RapidSMS tracks mothers and infants through two years of age. Based on pregnancy-specific information, the RapidSMS system generates and sends SMS reminders to CHWs, along with the pairs (mother/infant) they are tasked to follow up, dates for clinical appointments including antenatal visits, delivery and postnatal care visits [14]. By tracking pregnancies and providing reminders, RapidSMS could potentially increase 
utilization of recommended maternal and newborn healthcare services including antenatal care visits, health facility deliveries, receipt of postnatal care, and immunizations.

While maternal newborn and child health has considerably improved across Rwanda over the past several years, 10/30 districts lagged behind and, therefore, benefited from additional support from UNICEF including CHWs training and quarterly supervision meetings [18]. When CHWs report danger signs, the RapidSMS system generates an emergency alert system (RED alert notification system) comprising of "immediate feedback to the CHW advising on immediate action" [14]. Furthermore, it sends an ambulance request to the closest ambulance vehicle point [14]. Rwanda is divided into 30 districts and the RapidSMS program was implemented across these districts at different time points. While 29 districts scaled up the program at different points in 2013, one district (Musanze) did so in 2010 [14] and was therefore excluded from our evaluation.

\section{Data source}

We investigated the impact of the implementation of RapidSMS on uptake of maternal and newborn healthcare services including antenatal care visits, health facility deliveries, and immunizations. Our data came from the Rwanda Demographic and Health Survey (RDHS) [9]. The RDHS is a population-based cross-sectional survey carried out every five years by the National Institute of Statistics of Rwanda in collaboration with the DHS Program ICF International using complex multi-stage sampling to gather a nationally representative sample [9]. Through face-to-face interviews, this survey collects data including on health services utilization across the continuum of care for maternal, newborn and child health [9]. The most recent wave of RDHS (2014/15 RDHS) was carried out from November 2014 to April 2015 and is a nationally representative survey of 12,699 households, 13,497 women aged 15-49 years and 6217 men aged 15-59 years [9]. The 2014/15 RDHS collected data covering five years preceding the survey (20102014) [9].

For this program analysis, we analyzed aggregated data from 24 months prior to RapidSMS implementation and 18 months following the implementation of the RapidSMS program across the 29 districts. This length of study time provided adequate data points to construct our longitudinal models [19], as described in the statistical analysis sub-section below.

\section{Study cohort}

Using the RDHS, we identified a cohort of women aged 15-49 years who had a live birth within five years preceding the survey. Using the date of childbirth, we selected births that occurred in the study time and also extracted self-reported information pertaining to healthcare utilization by mothers and newborns, including ANC visits, place of delivery and vaccination coverage. Our unity of observation is the person-month.

\section{Outcome measures}

We studied the impact of RapidSMS on 6 outcomes within the following 3 categories:

- Antenatal care: We calculated the number of ANC (at least one visit), the number of ANC (at least four visits) and the number of timely ANC (first ANC in the first trimester) per 100 live births in our cohort.

- Health facility delivery: We calculated the number of delivery at a health facility (also used as a proxy for skilled birth attendants) per 100 live births;

- Vaccination: We calculated the number of newborns who received BCG vaccine for prevention of tuberculosis and those who received Polio 0 vaccine for prevention of poliomyelitis infection per 100 live births. These two vaccines are part of Rwandan routine immunization program and are given to newborns at birth [20].

\section{Design and statistical analysis}

Using interrupted time series (ITS) design-one of the strongest quasi-experimental designs [19]—we assessed the impact of the RapidSMS program on uptake of maternal and newborn healthcare services including antenatal care visits, health facility deliveries, and vaccinations. Interrupted time series analysis has widely been used in program and policy evaluation in healthcare [19]. To fit our statistical models, we first determined the proportion for each outcome across all person-months in our dataset as described earlier. Using these aggregate proportions, we fitted segmented regression models for each outcome of interest to estimate changes in level and trend associated with the implementation of the RapidSMS program. Our ITS models took the following general form to model each outcome of interest for program status $j$, at time $t$ :

$$
\text { Outcome }_{j t}=\beta_{0}+\beta_{1} \cdot \text { time }_{t}+\beta_{2} \cdot \text { level }_{j}+\beta_{3} \cdot \text { trend }_{j t}+\varepsilon_{j t}
$$

Where outcome represents each outcome measure of interest as described earlier (e.g. ANC visit at least once during pregnancy, health facility delivery, vaccination); time is the month in study time at time $t$ (i.e. $1,2,3$, 4 ...); level represents whether the RapidSMS program was in place in month; and trend represents the month $t$ it was after the program implementation. In each ITS model, $\beta_{0}$ estimated the baseline uptake of maternal and newborn health services evaluated; $\beta_{1}$ estimated monthly 
trend in the uptake in the period before RapidSMS. For this program analysis, the two coefficients of interest are $\beta_{2}$, which indicates any immediate change in the level of each of our outcome of interest after the implementation of RapidSMS, and $\beta_{3}$, which indicates any change in the monthly trend in the outcome after the implementation of RapidSMS compared to the trend before RapidSMS. Statistically significant values for these coefficients $\left(\beta_{2}\right.$ and/or $\left.\beta_{3}\right)$ would indicate that the RapidSMS program had an impact on uptake of maternal and newborn health services analyzed. $\varepsilon_{j t}$ is the error term representing the variability not explained by the model. As monthly observations may have been correlated over time, we assessed for autocorrelation using Durbin-Watson test and visual plots (autocorrelation function and partial autocorrelation function) and controlled for autocorrelation using appropriate adjustments in a generalized least squares model [19]. Given the RapidSMS program was scaled up across the 29 districts at different times in 2013, we conducted all analyses using study time (the number of months relative to each district's month of RapidSMS implementation) to standardize each district to the others based their individual start date. All analyses were weighted to account for the complex multi-stage sampling design of RHDS. All analyses were performed using $\mathrm{R}$ version 3.4.4 [21].

\section{Results}

\section{Descriptive characteristics}

The descriptive characteristics and responses regarding health services use are shown in Table 1 . Nearly all respondents had at least one ANC visit during their most recent pregnancy and had their newborns vaccinated for tuberculosis (BCG). Unadjusted rates for early antenatal care (first ANC visit in the first trimester) and delivery at a health facility were highest among younger women, those with post-secondary education, those who were married or in union, and those in the highest wealth quintile.

\section{Effect on antenatal care (ANC) visit}

We examined the rate (\%) of women with a live birth who had had at least one ANC visit during their most recent pregnancy. The baseline rate of ANC visit at least once during pregnancy was very high at $98.66 \%$ (95\%

Table 1 Sociodemographic characteristics and health services use among respondents to the Rwanda Demographic and Health Survey, November 2014-April 2015

\begin{tabular}{|c|c|c|c|c|c|c|c|}
\hline & Overall sample $(N=7766)$ & $\begin{array}{l}\text { Antenatal care } \\
\text { (at least } 1 \text { visit) }\end{array}$ & $\begin{array}{l}\text { Antenatal care } \\
\text { (at least } 4 \text { visits) }\end{array}$ & $\begin{array}{c}\text { Antenatal care } \\
\text { (in the } 1 \text { st trimester) }\end{array}$ & $\begin{array}{c}\text { Health facility } \\
\text { delivery }\end{array}$ & BCG vaccination & $\begin{array}{l}\text { Polio } 0 \\
\text { vaccination }\end{array}$ \\
\hline & $n(\%)$ & $\%$ & $\%$ & $\%$ & $\%$ & $\%$ & $\%$ \\
\hline \multicolumn{8}{|l|}{ Maternal age } \\
\hline $15-29$ years & $3802(49.0)$ & 99.07 & 45.78 & 61.69 & 94.01 & 98.29 & 90.57 \\
\hline $30-49$ years & $3964(51.0)$ & 99.23 & 41.95 & 51.74 & 87.27 & 98.17 & 90.46 \\
\hline \multicolumn{8}{|l|}{ Education } \\
\hline no education & $1156(14.9)$ & 98.28 & 36.96 & 48.65 & 81.92 & 97.04 & 85.15 \\
\hline primary & $5627(72.5)$ & 99.29 & 44.07 & 56.35 & 91.23 & 98.24 & 90.73 \\
\hline secondary & $824(10.6)$ & 99.23 & 45.25 & 63.14 & 96.74 & 99.71 & 94.95 \\
\hline post-secondary & $158(2.0)$ & 99.76 & 74.17 & 82.85 & 98.17 & 98.54 & 97.28 \\
\hline \multicolumn{8}{|l|}{ Place of residence } \\
\hline urban & $1272(16.4)$ & 98.78 & 43.90 & 56.48 & 96.94 & 98.25 & 94.77 \\
\hline rural & 6494 (83.6) & 99.22 & 43.80 & 56.62 & 89.32 & 98.22 & 89.67 \\
\hline \multicolumn{8}{|l|}{ Married } \\
\hline no & $1388(17.9)$ & 98.38 & 37.08 & 51.54 & 89.98 & 97.72 & 89.29 \\
\hline yes & $6378(82.1)$ & 99.35 & 45.54 & 57.87 & 90.7 & 98.34 & 90.78 \\
\hline \multicolumn{8}{|l|}{ Wealth quintile } \\
\hline lowest & $1891(24.4)$ & 98.73 & 41.35 & 54.61 & 83.99 & 97.76 & 86.74 \\
\hline second & 1676 (21.6) & 99.24 & 43.55 & 55.00 & 90.96 & 98.03 & 88.80 \\
\hline middle & 1530 (19.7) & 99.21 & 45.17 & 57.93 & 90.64 & 98.46 & 92.24 \\
\hline fourth & $1340(17.3)$ & 99.7 & 45.49 & 57.99 & 92.77 & 98.19 & 91.13 \\
\hline highest & $1327(17.1)$ & 98.99 & 44.3 & 58.32 & 97.16 & 98.89 & 95.28 \\
\hline
\end{tabular}

${ }^{a}$ All estimates are weighted to account for the Rwanda demographic and health survey design. Our study sample included data from $29 / 30$ Rwandan districts which scaled up RapidSMS in 2013 
confidence interval [CI]: 97.77 to 99.55) (Table 2). As indicated in the Fig. 1 and Table 2, we unsurprisingly found no significant changes in either the level or trend of the receipt of at least one ANC visit during pregnancy (level change: $-1.00,95 \% \mathrm{CI}:-2.30$ to 0.29 and trend: $-0.04,95 \%$ CI: -0.14 to 0.06 ). Given the very high level of reported ANC attendance prior to RapidSMS, there was little improvement left to be made on this indicator.

We also examined the rate (\%) of women who completed the recommended standard regimen of 4 ANC visits (or more) during their most recent pregnancy. The baseline rate of 4+ ANC visits was 40.57\% (95\% CI: 34.96 to 46.17) (Table 2). As shown in the Fig. 2 and Table 2, we did not find that the start of RapidSMS was associated with an improvement in level and trend in 4+ ANC visits (level change: $-1.69,95 \% \mathrm{CI}$ : -9.94 to 6.55 and trend: $-0.40,95 \% \mathrm{CI}:-1.09$ to 0.27 ). Similarly, we examined the rate of women who had the first ANC visit in the first trimester of the pregnancy (Table 2 and Fig. 3). We did not find evidence that the implementation of RapidSMS was associated with an improvement in level and trend in first ANC visit during the first trimester of the pregnancy (level change: $-3.80,95 \% \mathrm{CI}:-13.66$ to 6.05 and trend: -0.62 , 95\% CI: -1.43 to 0.19) (Table 2 and Fig. 3).

\section{Effect on health facility delivery}

We examined the rate (\%) of women with a live birth who delivered at a health facility for their most recent childbirth. As with 1+ ANC visit, the baseline rate of health facility delivery was quite high at 90.25 (95\% CI: 87.27 to 93.22) (Table 2). As shown in the Fig. 4, we found no significant changes in either the level or trend in delivery at a health facility (level change: $-1.79,95 \%$ CI: -6.16 to 2.58 and trend: $-0.13,95 \% \mathrm{CI}:-0.49$ to 0.22 ).

\section{Effect on newborn vaccination}

We examined the vaccination coverage rate (\%) of BCG (for tuberculosis) and Polio 0 for newborns whose birth occurred in the study time. The baseline coverage rate was very high for both BCG and Polio 0 (98.57\% (95\% CI: 97.92 to 99.21 ) and $91.35 \%$ (95\% CI: 87.66 to 95.04 ), respectively) (Table 2). As shown in the Figs. 5, 6 and Table 2, we found no significant changes in either the level or trend in BCG and Polio 0 vaccination coverage.

\section{Discussion}

The current evaluative research was undertaken to assess the impact of the RapidSMS program on utilization of maternal and newborn health services including antenatal care visits, institutional deliveries, and vaccination coverage (BCG and polio 0) in Rwanda. Based on our analysis using the most recent wave of the Rwanda Demographic and Health Survey, it appears that the implementation of RapidSMS program did not increase uptake (immediately and over time) of the maternal and newborn health services we studied. In most instances, this was because the existing level of the indicators we studied was very high (ceiling effect), leaving little room for potential improvement.

With increasing access to mobile phone worldwide, implementation of mhealth interventions have been advocated as one of the approaches to improve population health and, approximately $83 \%$ of WHO member countries reported having at least one mhealth initiative in 2016 [16, 22, 23]. While hundreds of mhealth interventions have been piloted, little is known about their potential effectiveness at a large scale [16, 22]. During the pilot stage, RapidSMS was found to be associated with increase in the proportion of deliveries occurring in health facilities in Musanze district [14]; however, we found no evidence that the same indicator improved following the nationwide scale-up period. This highlights the importance of evaluating programs regularly even those that were found to be effective at the pilot stage in order to identify potential factors (facilitators and barriers) to their successful adoption and scale-up over time. Nevertheless, RapidSMS may work in contexts

Table 2 Baseline coverage rate and change in level and trend for each outcome analyzed

\begin{tabular}{|c|c|c|c|c|c|c|c|}
\hline Outcome measures & $\begin{array}{l}\text { Baseline coverage } \\
\text { rate }(95 \% \mathrm{Cl})\end{array}$ & $\begin{array}{l}\text { Pre- RapidSMS } \\
\text { trend }(95 \% \mathrm{Cl})\end{array}$ & $P$ value & Level change $(95 \% \mathrm{Cl})$ & $P$ value & $\begin{array}{l}\text { Post-RapidSMS } \\
\text { trend }(95 \% \mathrm{Cl})\end{array}$ & $P$ value \\
\hline \multicolumn{8}{|l|}{ Antenatal care (ANC) } \\
\hline ANC (at least one visit) & 98.66 (97.77 to 99.55) & $0.04(-0.01$ to 0.10$)$ & 0.1 & $-1.00(-2.30$ to 0.29$)$ & 0.1 & $-0.04(-0.14$ to 0.06$)$ & 0.4 \\
\hline ANC (at least four visits) & 40.57 (34.96 to 46.17) & $0.29(-0.09$ to 0.68$)$ & 0.1 & $-1.69(-9.94$ to 6.55$)$ & 0.6 & $-0.40(-1.09,0.27)$ & 0.2 \\
\hline $\begin{array}{l}\text { ANC visit in the first } \\
\text { trimester }\end{array}$ & 50.30 (43.60 to 57.00$)$ & 0.52 (0.05 to 0.99$)$ & 0.02 & $-3.80(-13.66$ to 6.05$)$ & 0.4 & $-0.62(-1.43$ to 0.19$)$ & 0.1 \\
\hline \multicolumn{8}{|l|}{ Childbirth } \\
\hline Health facility delivery & 90.25 (87.27 to 93.22 ) & $0.11(-0.09$ to 0.32$)$ & 0.2 & $-1.79(-6.16$ to 2.58$)$ & 0.4 & $-0.13(-0.49$ to 0.22$)$ & 0.4 \\
\hline \multicolumn{8}{|l|}{ Immunization } \\
\hline BCG & 98.57 (97.92 to 99.21$)$ & $-0.01(-0.05$ to 0.03$)$ & 0.5 & $0.58(-0.38$ to 1.55$)$ & 0.2 & $-0.01(-0.09$ to 0.06$)$ & 0.6 \\
\hline Polio 0 & 91.35 (87.66 to 95.04 ) & $-0.01(-0.27$ to 0.23$)$ & 0.8 & $-0.75(-6.18$ to 4.67$)$ & 0.7 & $0.13(-0.31$ to 0.58$)$ & 0.5 \\
\hline
\end{tabular}




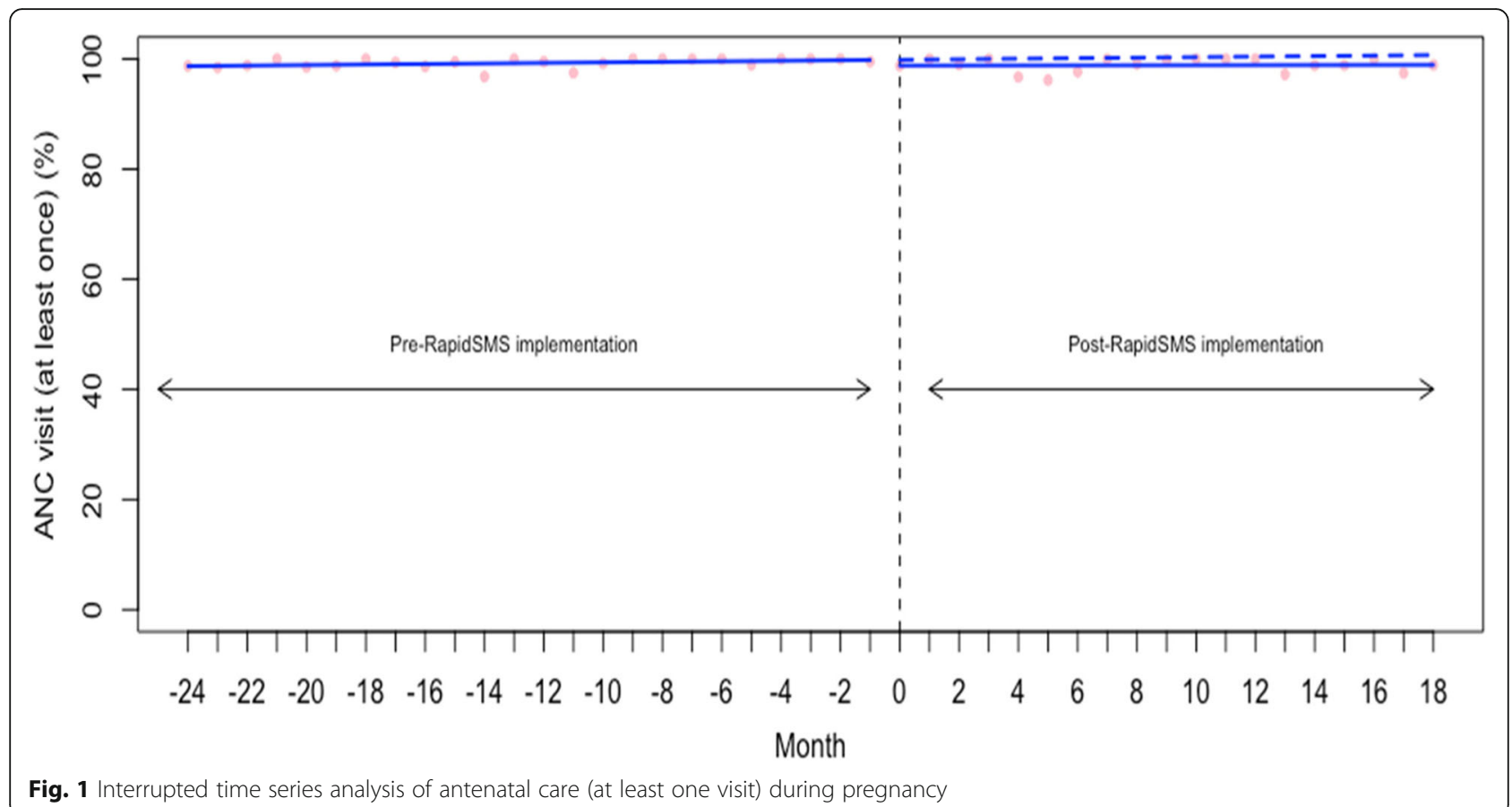

where improvement remains to be made, but not for indicators that are already very high.

The existing rates of the uptake for ANC visits (at least once), institutional deliveries and vaccination coverage were very high at over $90 \%$, leaving little room for potential improvement. However, the rate of women who completed the recommended standard regimen of 4 ANC visits (or more) during their most recent pregnancy
(40.57\%) and the rate of women who had the first ANC visit in the trimester (50.30\%) were suboptimal and they did not appear to have increased following RapidSMS implementation. Although further research would be required to understand why RapidSMS had no impact on these indicators where there was enough room for improvement, we believe that the lack of impact could be explained, on the one hand, by the fact that the RapidSMS

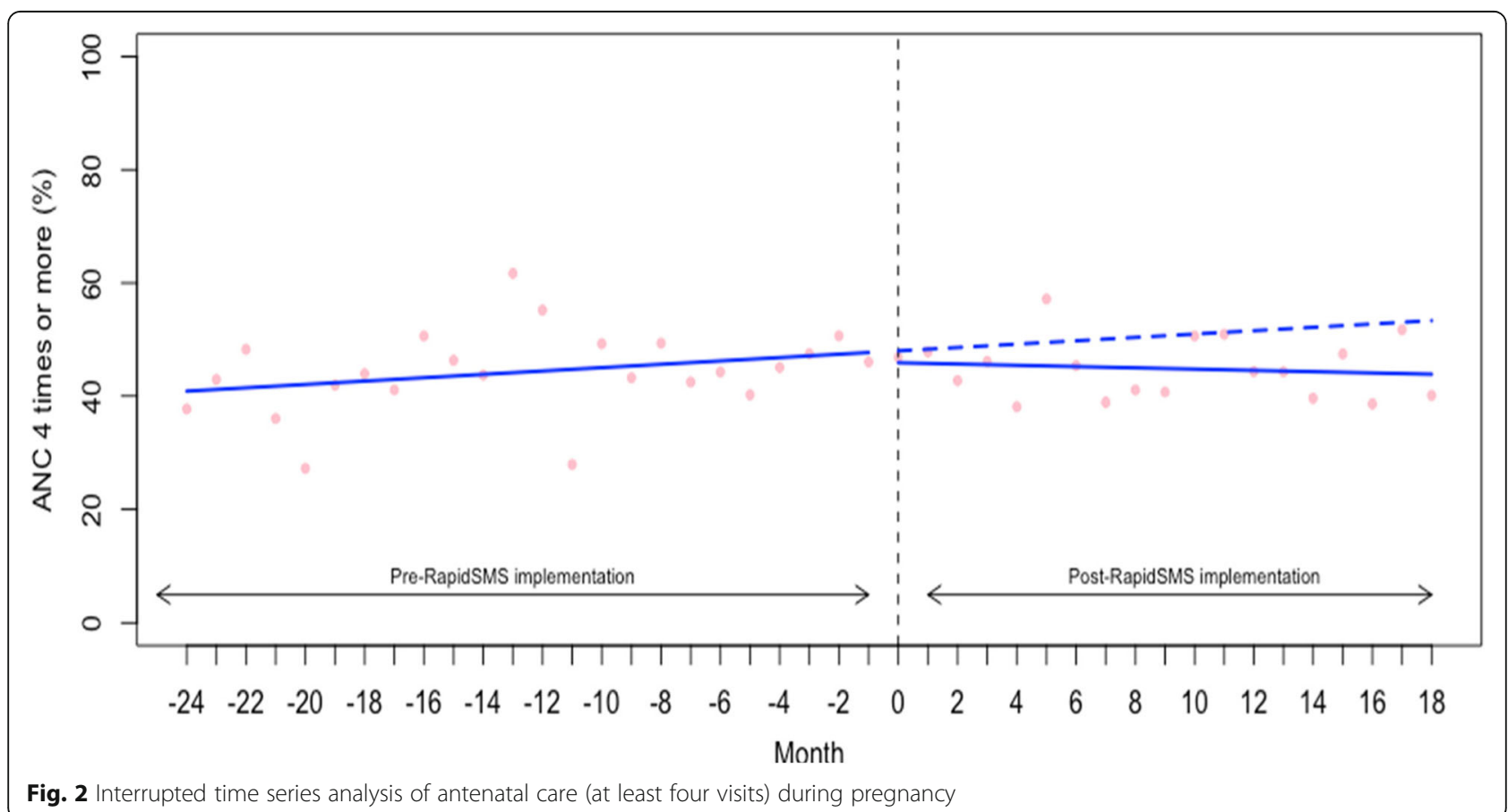

Fig. 2 Interrupted time series analysis of antenatal care (at least four visits) during pregnancy 


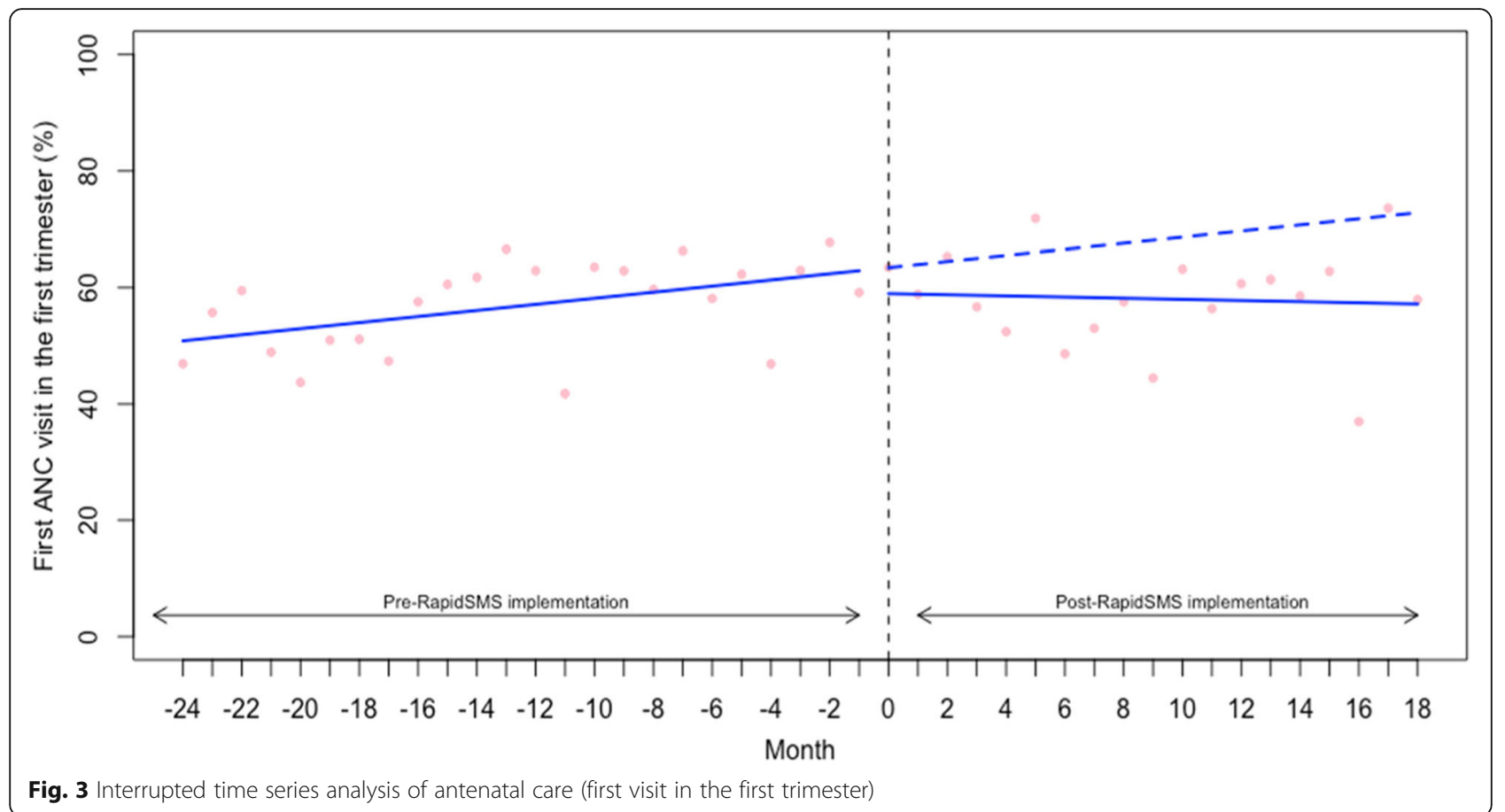

program was not implemented with perfect fidelity. For example, Musabyimana et al. (2018) qualitative study undertaken in Rwanda to gather the experiences of the RapidSMS program implementers as well as community health workers with implementing RapidSMS identified challenges to successful implementation of RapidSMS including lack of motivation and high turn-over of CHWs, lack of regular CHW training and incentives [24]. Similarly, Condo et al. (2014) identified several other factors (e.g., overwhelming workload and lack of supervision) that could hamper the effectiveness of the Rwandan community health program [25]. This highlights the importance of context and the reality that interventions are rarely implemented with perfect fidelity [26-28].

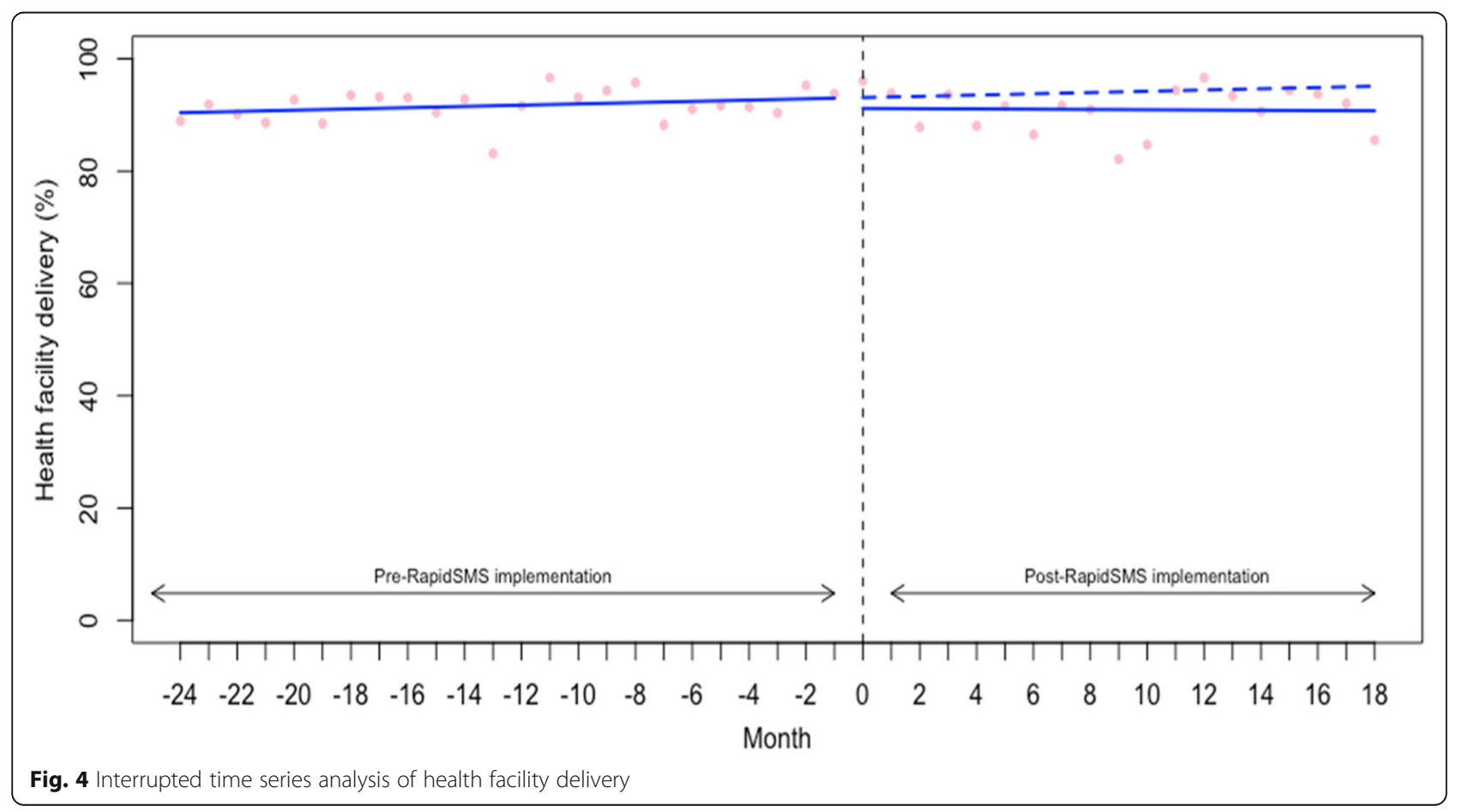




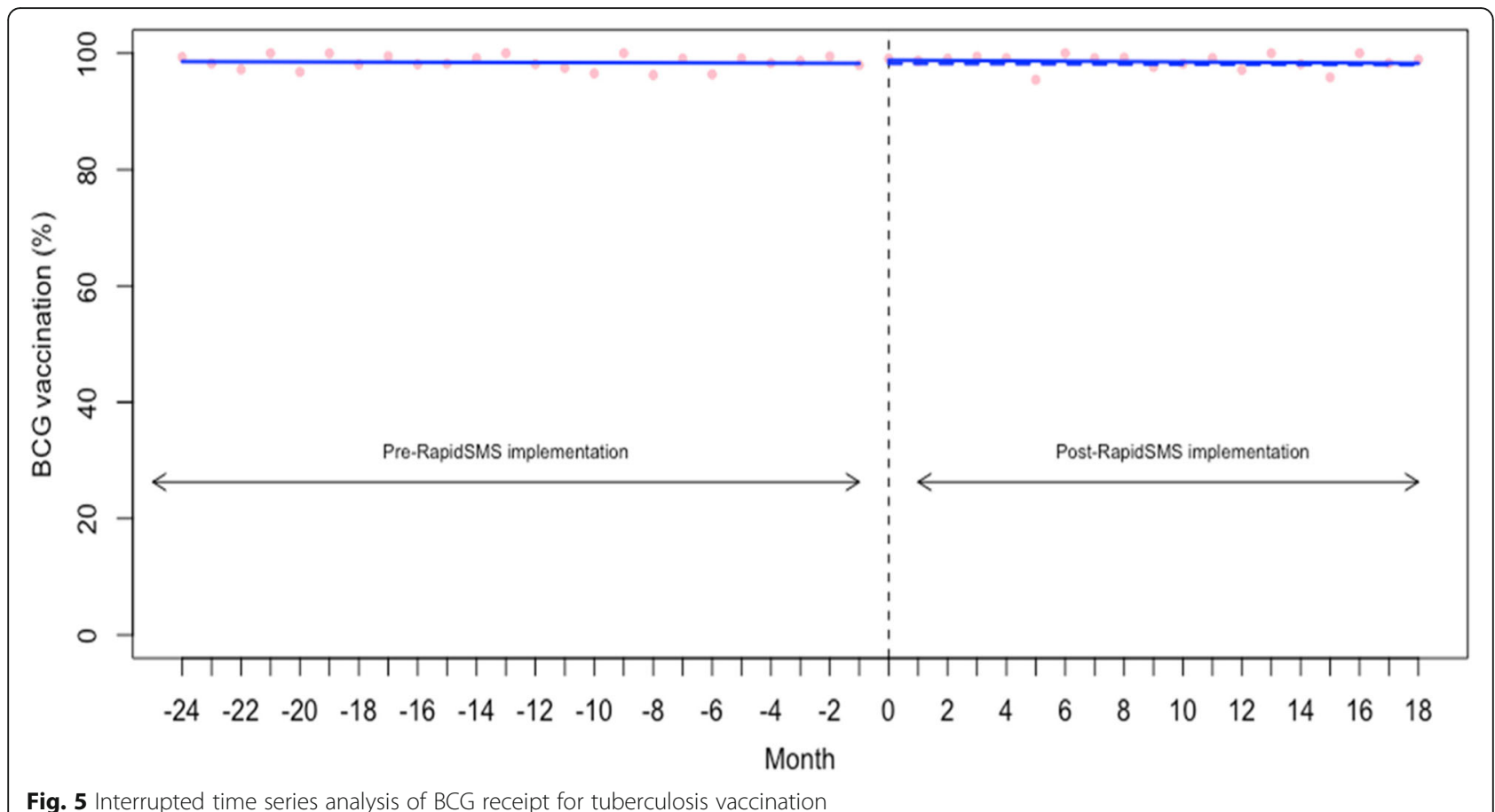

Going forward, effective RapidSMS implementation strategies should be explored as well as targeting meaningful areas for improvements to be made. For example, given the high penetrance of mobile phones in Rwanda, one may consider using patient-centered SMS reminder as opposite to sending reminders to CHWs. Also, addressing implementation challenges including training and incentivizing CHWs may be helpful [24]. On the other hand, factors beyond the RapidSMS program could also be the reason behind the lack of impact on the indicators where there still was enough room for improvement. For example, growing evidence suggests that women who are not satisfied by the quality of care, including disrespect, they get during their first ANC visits

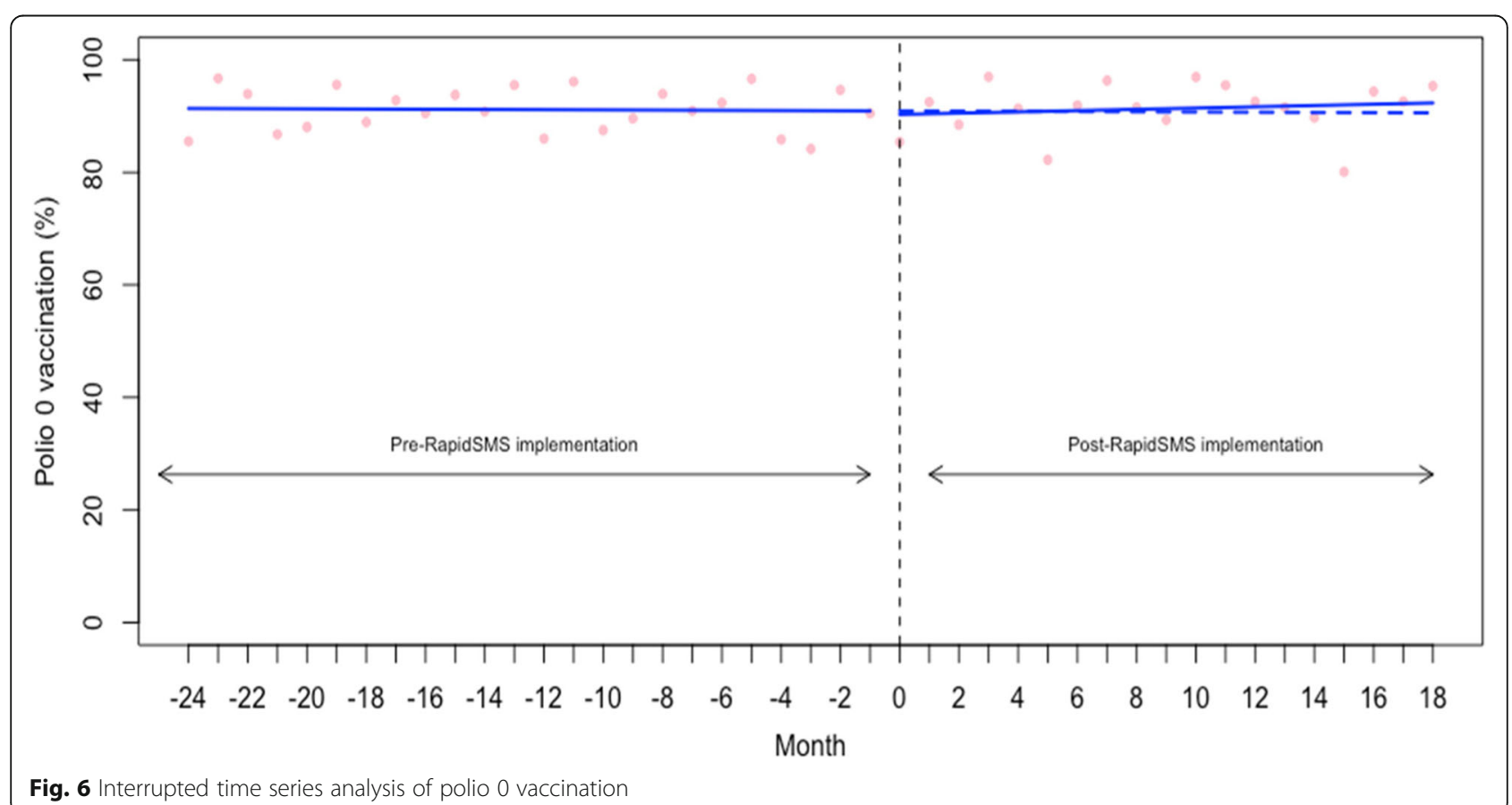

Fig. 6 Interrupted time series analysis of polio 0 vaccination 
may not come back to health facility for additional ANC visits in order to complete the recommended standard regimen of 4 ANC visits [29]. Growing evidence suggests that quality of health care provided in Rwandan health facilities, like in many other LMICs, is not optimal [3034]. Delaying in seeking antenatal care (not having first ANC during the first trimester of the pregnancy) has been linked to several factors including knowledge gap, insufficient male involvement in ANC, family income, and maternal age [35-37]. These factors may not be affected by an mhealth intervention such as RapidSMS.

Our findings are consistent with the findings from a concurrent evaluation of the RapidSMS program in Rwanda using routinely collected data from all health facilities across Rwanda (Rwanda Health Management Information System (RHMIS)) and data in the RapidSMS database captured by the community health workers (CHWs) tasked to follow up pairs of mother-infant in their villages in Rwanda [18]. Based on analysis of RHMIS and RapidSMS databases, it was found that the start of RapidSMS had no significant impact on the proportion of women receiving antenatal care in Rwanda [18]. Moreover, the proportion of women delivering at the health facility and that of newborn and mothers receiving postnatal care did not appear to have increased following the implementation of RapidSMS across 20 districts that did not benefit from further $\mathrm{CHW}$ training and quarterly supervision [18]. It should be noted that the same indicators improved in the 10 districts that received additional support described earlier [18]. With the size of our sample, we were unable to perform a stratified analysis to formally test whether the impact of RapidSMS differed by the additional support received. Therefore, any impact in the smaller number of supported districts may have been washed out in our national data.

Previous research on the impact of mhealth interventions in other LMICs found increasing evidence around effectiveness of mhealth spanning patient adherence to HIV and tuberculosis treatment and, also healthcare workers' adherence to treatment guidelines [38-40]. Similarly, in their recent systematic review $(n=17$ mhealth studies included), Lee and colleagues (2016) looked at the effectiveness of mhealth interventions for maternal, newborn and child health in developing world and found evidence that mhealth interventions using SMS increased the rates of initial breastfeeding and exclusive breastfeeding [41]. However, they found no conclusive evidence on the impact of mhealth interventions on utilization of healthcare services (e.g., ANC, health facility delivery, and vaccination) and on maternal, neonatal and child mortality [41]. It is worthy noting that most of the mhealth studies included in Lee et al's review were of poor methodological quality [41]. Flaws at the design/implementation stage make it difficult for evaluators to conduct rigorous evaluation. It is advisable for mhealth program implementers to work hand in glove with evaluators to ensure the way mhealth programs are implemented offer opportunity for rigous evaluation. It is also important to evaluate the real-world experiences with implementation of mhealth interventions in order to understand why mheath interventions appear to be effective only in some contexts.

This study has several strengths including use of a nationally representative sample and use of one of the strongest quasi-experimental designs (ITS) that, unlike pre-post design, allowed controlling for pre-existing trends in utilization of maternal and newborn health services [19]. However, the current findings should still be interpreted with caution given potential study limitations. First, given that the survey was carried out from November 2014 to April 2015 and respondents were asked to report information that took place within five years before the survey, recall bias cannot be ruled out. This recall bias might have affected the pre-intervention and post intervention differentially and, thus, introducing differential misclassification bias on our outcome measures. However, this would bias us toward finding an impact and we found none. Similarly, we could not rule out the possibility of social desirability bias that could have affected the reporting health services use. Second, there are other relevant indicators (e.g., neonatal and maternal referrals to higher levels of care, and outcomes of care provided) that we could have examined that are not in RHDS. Lastly, our sample size was not large enough to allow us to perform a stratified analysis to study whether the impact of RapidSMS differed by the additional UNICEF support described earlier. However, we were able to generate reasonably stable monthly estimates to study the impact of RapidSMS nationwide.

In conclusion, based on our analysis using national representation survey data, we found that the implementation of RapidSMS did not increase uptake of the maternal and newborn health services we studied in Rwanda. In most instances this was the result of our indicators being very high, leaving little room for further improvement. Sustainable reduction of maternal and neonatal mortality in line with the SDG targets would certainly require increasing coverage of proven effective maternal and newborn interventions across the continuum of care. As such, exploring effective implementation strategies, including well designed mhealth interventions, that are likely to improve coverage of life-saving maternal and newborn interventions is warranted. Equally important is rigorous evaluation of such interventions to guide policy decisions including scale up over time. 


\section{Acknowledgements}

Data used in this study were obtained from the DHS Program; however, all inferences, opinions, and conclusions drawn in this article are those of the authors, and do not reflect the opinions of DHS. Dr. Hategeka is supported by a Vanier Canada Graduate Scholarship and a University of British Columbia Four Year Doctoral Fellowship. Mr. Ruton is supported by a University of British Columbia Four Year Doctoral Fellowship. Dr. Law received salary support through a Canada Research Chair in Access to Medicines and a Michael Smith Foundation for Health Research Scholar Award. Abstract "Evaluating the impact of an SMS-based alert system (RapidSMS-MCH) on uptake of maternal, newborn and child healthcare services in Rwanda: a quasi-experimental design using Rwanda demographic and health survey" was presented during the 2017 American Academy of Pediatrics (AAP) National Conference \& Exhibition in Chicago, USA.

\section{Funding}

This study was not funded.

\section{Availability of data and materials}

All data used in this analysis are publicly available from the Demographic and Health Survey Program (http://www.dhsprogram.com).

\section{Authors' contributions}

$\mathrm{CH}$ developed the research question and the empirical approach, analyzed the data and wrote the first draft of the manuscript. ML provided guidance throughout the research process. All authors reviewed the manuscript for important intellectual content and approved the final manuscript.

\section{Ethics approval and consent to participate}

Data used in this study were obtained from the DHS Program (https:// dhsprogram.com/data/available-datasets.cfm). Ethics approval for the use of the DHS data is covered by the "publicly available data clause (Item 7.10.3)" under the "policy number 89 of the University of British Columbia, Vancouver, BC, Canada: Research and Other Studies Involving Human Subjects" that regulates the use of public release data (https://universitycounsel.ubc.ca/files/2012/06/policy89.pdf).

\section{Consent for publication}

Not applicable.

\section{Competing interests}

The authors declare that they have no competing interests.

\section{Author details}

${ }^{1}$ Centre for Health Services and Policy Research, Faculty of Medicine, School of Population and Public Health, The University of British Columbia, 201-2206 East Mall, Vancouver, BC V6T1Z3, Canada. ${ }^{2}$ Collaboration for Outcomes Research and Evaluation, Faculty of Pharmaceutical Sciences, The University of British Columbia, Vancouver, BC, Canada. ${ }^{3}$ School of Public Health, College of Medicine and Health Sciences, University of Rwanda, Kigali, Rwanda.

Received: 8 December 2018 Accepted: 25 February 2019

Published online: 22 March 2019

\section{References}

1. World Health Organization. Trends in maternal mortality: 1990-2015: estimates from WHO, UNICEF, UNFPA, World Bank Group and the United Nations Population Division: executive summary. 2015.

2. You D, Hug L, Ejdemyr S, Idele P, Hogan D, Mathers C, et al. Global, regional, and national levels and trends in under-5 mortality between 1990 and 2015, with scenario-based projections to 2030: a systematic analysis by the UN inter-agency Group for Child Mortality Estimation. Lancet. 2015; 386(10010):2275-86.

3. United Nations. Millennium development goals 20002000 [October 20, 2016]. Available from: http://www.un.org/millenniumgoals/childhealth.shtml.

4. United Nations. The millennium development goals report 2015. 2015

5. Abbott P, Sapsford R, Binagwaho A. Learning from success: how Rwanda achieved the millennium development goals for health. World Dev. 2017;92: 103-16

6. National Institute of Statistics of Rwanda MoHR, ICF International.. Rwanda Demographic and Health Survey 2010. 2012.
7. Farmer PE, Nutt CT, Wagner CM, Sekabaraga C, Nuthulaganti T, Weigel JL, et al. Reduced premature mortality in Rwanda: lessons from success. BMJ. 2013;346:f65.

8. Bhutta ZA, Das JK, Bahl R, Lawn JE, Salam RA, Paul VK, et al. Can available interventions end preventable deaths in mothers, newborn babies, and stillbirths, and at what cost? Lancet. 2014;384(9940):347-70.

9. National Institute of Statistics of Rwanda (NISR) [Rwanda], Ministry of Health $(\mathrm{MOH})$ [Rwanda], and ICF International. Rwanda Demographic and Health Survey 2014-15. 2015.

10. Lim SS, Allen K, Bhutta ZA, Dandona L, Forouzanfar MH, Fullman N, et al. Measuring the health-related sustainable development goals in 188 countries: a baseline analysis from the global burden of disease study 2015. Lancet. 2016:388(10053):1813-50.

11. Ministry of Health $(\mathrm{MOH})$ [Rwanda]. Rwanda Annual Health Statistics Booklet. 2013.

12. Sayinzoga F, Bijlmakers L, van Dillen J, Mivumbi V, Ngabo F, van der Velden K. Maternal death audit in Rwanda 2009-2013: a nationwide facility-based retrospective cohort study. BMJ Open. 2016;6(1):e009734.

13. World Health Organization. Every newborn: an action plan to end preventable deaths. 2014.

14. Ngabo F, Nguimfack J, Nwaigwe F, Mugeni C, Muhoza D, Wilson DR, Kalach J, Gakuba R, Karema C, Binagwaho A. Designing and Implementing an Innovative SMS-based alert system (RapidSMS-MCH) to monitor pregnancy and reduce maternal and child deaths in Rwanda. Pan Afr Med J. 2012;13:31.

15. UNICEF. RapidSMS 2013 2016. Available from: https://www.rapidsms.org/ about/.

16. World Health Organization. Global diffusion of eHealth: making universal health coverage achievable: report of the third global survey on eHealth. 2016.

17. National Institute of Statistics of Rwanda. Rwanda Population and Housing Census (RPHC4) Thematic Report: Population Size, Structure and Distribution.; 2014.

18. Ruton H, Musabyimana A, Gaju E, Berhe A, Grépin KA, Ngenzi J, et al. The impact of an mHealth monitoring system on health care utilization by mothers and children: an evaluation using routine health information in Rwanda. Health Policy Plan. 2018;33(8):920-7.

19. Wagner AK, Soumerai SB, Zhang F, Ross-Degnan D. Segmented regression analysis of interrupted time series studies in medication use research. J Clin Pharm Ther. 2002:27(4):299-309.

20. Ministry of Health Rwanda. Expanded Program on Immunization: Comprehensive mult-year plan 2011-2015. 2011.

21. Team RC. The R Foundation for Statistical Computing Platform. 2018;3(1).

22. Tomlinson M, Rotheram-Borus MJ, Swartz L, Tsai AC. Scaling up mHealth: where is the evidence? PLoS Med. 2013;10(2):e1001382.

23. Kruk ME, Kujawski S, Moyer CA, Adanu RM, Afsana K, Cohen J, et al. Next generation maternal health: external shocks and health-system innovations. Lancet. 2016;388(10057):2296-306.

24. Musabyimana A, Ruton H, Gaju E, Berhe A, Grépin KA, Ngenzi J, et al. Assessing the perspectives of users and beneficiaries of a community health worker mHealth tracking system for mothers and children in Rwanda. PLoS One. 2018;13(6):e0198725.

25. Condo J, Mugeni C, Naughton B, Hall K, Tuazon MA, Omwega A, et al. Rwanda's evolving community health worker system: a qualitative assessment of client and provider perspectives. Hum Resour Health. 2014;12(1):71.

26. Hategeka C, Mwai L, Tuyisenge L. Implementing the emergency triage, assessment and treatment plus admission care (ETAT+) clinical practice guidelines to improve quality of hospital care in Rwandan district hospitals: healthcare workers' perspectives on relevance and challenges. BMC Health Serv Res. 2017;17(1):256.

27. Hategekimana C, Shoveller J, Tuyisenge L, Kenyon C, Cechetto DF, Lynd LD. Correlates of performance of healthcare workers in emergency, triage, assessment and treatment plus admission care (ETAT+) course in Rwanda: context matters. PLoS One. 2016;11(3):e0152882.

28. Tuyisenge G, Hategeka C, Luginaah I, Babenko-Mould Y, Cechetto D, Rulisa S. Continuing professional development in maternal health care: barriers to applying new knowledge and skills in the hospitals of Rwanda. Matern Child Health J. 2018:22(8):1200-7.

29. Sacks E, Langlois ÉV. Postnatal care: increasing coverage, equity, and quality. Lancet Glob Health. 2016;4(7):e442-e3.

30. Hategeka C, Shoveller J, Tuyisenge L, Lynd LD. Assessing process of paediatric care in a resource-limited setting: a cross-sectional audit of district hospitals in Rwanda. Paediatrics and international child health. 2018;38(2):137-45. 
31. Kabakambira JD, Niyonsenga Z, Hategeka M, Igiraneza G, Benurugo G, Lucero-Prisno DE III, et al. Blood pressure measurement techniques: assessing performance in outpatient settings of a tertiary-level hospital in Rwanda. J Clin Hypertens (Greenwich). 2018;20(6):1067-72.

32. Kruk ME, Leslie HH, Verguet S, Mbaruku GM, Adanu RM, Langer A. Quality of basic maternal care functions in health facilities of five African countries: an analysis of national health system surveys. Lancet Glob Health. 2016;4(11): e845-e55.

33. Kruk ME, Gage AD, Joseph NT, Danaei G, García-Saisó S, Salomon JA. Mortality due to low-quality health systems in the universal health coverage era: a systematic analysis of amenable deaths in 137 countries. Lancet. 2018; 392(10160):2203-12.

34. Kruk ME, Gage AD, Arsenault C, Jordan K, Leslie HH, Roder-DeWan S, et al. High-quality health systems in the sustainable development goals era: time for a revolution. Lancet Glob Health. 2018:6(11):e1196-e252.

35. Birmeta K, Dibaba Y, Woldeyohannes DJBhsr. Determinants of maternal health care utilization in Holeta town, central Ethiopia. BMC Health Serv Res. 2013;13(1):256

36. Hagey J, Rulisa S, Pérez-Escamilla RJM. Barriers and solutions for timely initiation of antenatal care in Kigali, Rwanda: Health facility professionals perspective. Midwifery. 2014;30(1):96-102.

37. Tuyisenge G, Hategeka C, Kasine Y, Luginaah I, Cechetto D, Rulisa SJW, et al. Mothers' perceptions and experiences of using maternal health care services in Rwanda. 2018(just-accepted).

38. Hall CS, Fottrell E, Wilkinson S, Byass P. Assessing the impact of mHealth interventions in low-and middle-income countries-what has been shown to work? Glob Health Action. 2014;7(1):25606.

39. Mahmud N, Rodriguez J, Nesbit J. A text message-based intervention to bridge the healthcare communication gap in the rural developing world. Technol Health Care. 2010;18(2):137-44.

40. Zurovac D, Sudoi RK, Akhwale WS, Ndiritu M, Hamer DH, Rowe AK, et al. The effect of mobile phone text-message reminders on Kenyan health workers' adherence to malaria treatment guidelines: a cluster randomised trial. Lancet. 2011;378(9793):795-803.

41. Lee SH, Nurmatov UB, Nwaru Bl, Mukherjee M, Grant L, Pagliari C Effectiveness of mHealth interventions for maternal, newborn and child health in low-and middle-income countries: systematic review and metaanalysis. J Glob Health. 2016;6(1):010401.

Ready to submit your research? Choose BMC and benefit from:

- fast, convenient online submission

- thorough peer review by experienced researchers in your field

- rapid publication on acceptance

- support for research data, including large and complex data types

- gold Open Access which fosters wider collaboration and increased citations

- maximum visibility for your research: over $100 \mathrm{M}$ website views per year

At $\mathrm{BMC}$, research is always in progress.

Learn more biomedcentral.com/submissions 